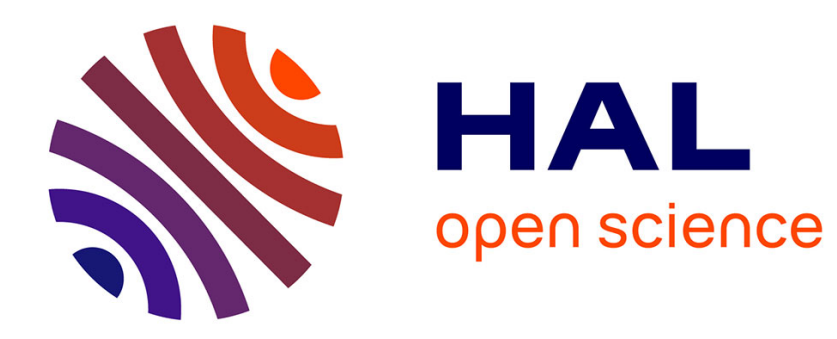

\title{
GRAIN BOUNDARIES IN POLYCRYSTALLINE ALUMINA
}

S. Lartigue, L. Priester

\section{To cite this version:}

S. Lartigue, L. Priester. GRAIN BOUNDARIES IN POLYCRYSTALLINE ALUMINA. Journal de Physique Colloques, 1985, 46 (C4), pp.C4-101-C4-106. 10.1051/jphyscol:1985410 . jpa-00224659

\section{HAL Id: jpa-00224659 https://hal.science/jpa-00224659}

Submitted on 1 Jan 1985

HAL is a multi-disciplinary open access archive for the deposit and dissemination of scientific research documents, whether they are published or not. The documents may come from teaching and research institutions in France or abroad, or from public or private research centers.
L'archive ouverte pluridisciplinaire HAL, est destinée au dépôt et à la diffusion de documents scientifiques de niveau recherche, publiés ou non, émanant des établissements d'enseignement et de recherche français ou étrangers, des laboratoires publics ou privés. 
JOURNAL DE PHYSIQUE

Colloque $\mathrm{C}_{4}$, supplément au $\mathrm{n}^{\circ} 4$, Tome 46, avril 1985

page $\mathrm{C} 4-101$

\title{
GRAIN BOUNDARIES IN POLYCRYSTALLINE ALUMINA
}

\author{
S. Lartigue and L. Priester ${ }^{+}$ \\ E.T.C.A., 94110 Arcueil, France \\ taboratoire de Métallurgie Physique, Bât. 413, Université Paris-Sud, \\ 91405 Orsay Cedex, France \\ Résumé - Une détermination statistique des types de joints de grains \\ 7 spéciaux et généraux) est effectuée dans deux alumines de différente \\ pureté. Les caractéristiques des joints de grains sont analysées : présence \\ de dislocations intrinsèques et extrinsèques, configuration facetée, \\ indices (densité) des plans de joints. \\ Abstract - The types of grain boundaries (special or not) have been \\ determined from a statistical point of view in two aluminas of different \\ purity. Grain boundary characteristics are anaryzed: presence of intrinsic \\ and extrinsic dislocations, faceted configurations and indices (density) \\ of the boundary planes.
}

In ceramics as well as in metals, the grain boundaries have an important influence on many properties of these materials, particularly mechanical and electrical properties. The properties that control the manufacture of ceramics ( sintering, grain growth ; not only depend on crystallographic structure of interfaces, but also may be strongly modified by segregated impurities.

One purpose of our research is the determination, from a statistical view point, of the tynes of boundaries ( special or not), found in sintered aluminas. As yet, most studies have been performed on ionic materials of cubic structure as MgO and $\mathrm{NiO}$, so the analysis of the structure of grain boundaries of an hexagonal material (boundary plane - faceting, defects) is of basic interest:it is our second purpose.

This paper sets out the first results obtained about grain boundary structure in two types of alumina. The first one is obtained from a powder of current purity, the second one is prepared from a high purity slurry.

Our description is based on the geometrical model of grain boundaries developed by Bollmann/1/. On the basis of this model relatively few studies exist in ionic materials as structural models are more complex than in metals. Furthermore, the charge of the ions influences the stability of the boundaries, and the presence of segregated impurities may contribute to this stabilization, as shown in a theoretical study /2/. With the development of X-Ray spectroscopy in A.E.M. , the chemical composition of an interface may be determined; that constitutes the third aim of our work to proceed to localized analytical electron microscopy on grain boundaries those crystallographic parameters are well established.

\section{I- EXPERIMENTAL}

First alumina (ref. A) has been obtained from powders ( $99 \%$ purity). It has been hot pressed at $1720^{\circ} \mathrm{C}$ under a pressure of $20 \mathrm{MPa}$, then heated at $1420^{\circ} \mathrm{C}$ for one our.

A purer alumina ( $99,99 \%$ purity) has been prepared from aluminium isopropoxide

Thanks to Mr. BIND ( ONERA) who prepared materials. 
AT $\left(\mathrm{OC}_{3} \mathrm{H}_{7}\right)_{3}$. A slurry is formed by mixing 3 moles of isopropoxide, 0,07 mole of $\mathrm{HNO}_{3}$ and 100 moles of deionized water. The slurry is calcined in air at $800^{\circ} \mathrm{C}$. Cylindrical samples are made by hot pressing at $1800^{\circ} \mathrm{C}$ in vacuum under a pressure of $25 \mathrm{MPa}$ for one hour. The material is then annealed at $1500^{\circ} \mathrm{C}$ for 24 hours to eliminate Carbon.

Alumina samples were cut using a diamond saw and mechanically polished to a thickness of about $80 \mu \mathrm{m}$. Thin foils were obtained by ion milling with a $5 \mathrm{kV}$ operating voltage. Finaliy, samples were coated with a thin layer of carbon to avoid charging in the microscope.

Our study is based on a geometrical approach of the coincidence. Delavignette has developed a method to establish tabulated coincidences for the hexagonal system /3/. For any axial ration $\mathrm{c} / \mathrm{a}$, the procedure gives the C.S.L. tables up to a maximum $\Sigma$ value of $35 . \Sigma$ is function of two integer parameters $\mu$ and $\nu$ such as $\mu / \nu=(\mathrm{c} / \mathrm{a})^{2}$. In the case of alumina where $\mathrm{c} / \mathrm{a}=2,73$, the closest $(\mu / p)^{1 / 2}$ value is equal to 2,739 . This is due to the non exactly close packing of oxygen atoms. We must distinguish between the exact C.S.L.'s, which are common to a11 hexagona] systems and correspond to rotations around [001] (written $\Sigma N_{\text {ex }}$ ), and near C.S.L.'s ( written $\Sigma N$ ). If different C.S.L. 's characterized by the same multiplicity exist, a distinction is made by addition of a small letter a,b,c..., in the increasing order with the value of the minimum rotation angle description. For all tabulated $\Sigma$, there is at least one description with a rotation angle of $180^{\circ}$. Practically, among all the descriptions, the Targest rotation angle is detected ; its deviation from $180^{\circ}$ gives a first idea about the possibility of coincidence. Then the corresponding rotation axis is compared with tabulated rotation axis ; grain boundary plane indices are also determined.

\section{II - RESULTS AND DISCUSSION}

The differences between the microstructures observed in both materials can be attributed not only to the difference of purity but also to the manufacture which is not strictly the same. Alumina $A$ has a well equilibrated microstructure and a typical grain size of $\simeq 10-20 \mu \mathrm{m}$. Porosity is observed at some triple points and sometimes at grain boundaries. No second phase particle has been detected. Alumina B has a strong heterogeneous microstructure; porosity occurs in the coarsest grains. The investigations of grain boundaries were made in the regions of small grains with similar size. Facets are more numerous than in $\mathrm{Al}_{2} \mathrm{O}_{3} \mathrm{~A}$ and there are a lot of boundaries making about $90^{\circ}$ dihedral angles, this last observation has been reported elsewhere in the case of highly pure alumina $/ 4 /$.

Three types of results have been obtained :

- the distribution of grain boundaries of each type "special " or "general "in the polycrystals,

- the observation of intrinsic and extrinsic dislocation networks in several boundaries

- the occurence of facets in some boundaries .

i) concerning the distribution of grain boundaries, in alumina $A$, among the 65 boundaries studied, 25 are special, including 21 close to a coincidence orientation, 2 small angles boundaries and 2 boundaries close to a basal twin orientation ( this twin is special as it does not modify the oxygen sub-lattice). In alumina $\mathrm{B}$, among 37 boundaries studied, 14 are special, including 11 close to a coincidence orientation and 3 low angle. We atso found 3 boundaries described by a $120^{\circ}$ rotation around an axis $54^{\circ}$ from (001). This rotation is analogous to the three - fold symmetry around [111] in cubic crystals. They have been called elsewhere "tri- perpendicular " ( or "orthoaxial ") boundaries $/ 5 /$.

Although the quantities of analyzed grain boundaries are different in the two mate- 
rials, it seems that more special boundaries occur in alumina $B$. In both cases, the relative number of special boundaries is important compared to those obtained in iron alloys with B.C.C. structure $/ 6,7 /$. This result agrees with a recent work where sintered materials present more special boundaries that materials produced either by cold working and annealing, or by orientated solidification /8/. It may be also correlated to the fact that alumina has a compact structure; a great number of special boundaries was recently detected in nickel /9/. From this point of view, it seems that F.C.C. and H.C. materials exhibit similar behaviour.

ii) A detailed observation of the microstructure of both materials reveals the occurrence of one or two dislocations arrays in 12 boundaries, those crystallographical description is given in Table 1.

\begin{tabular}{|c|c|c|c|c|c|}
\hline$n^{\circ}$ & $\begin{array}{l}\text { experimental } \\
\text { misorientation } \\
\theta[\text { UVTW }]\end{array}$ & $\begin{array}{l}\text { nearest } \\
\Sigma\end{array}$ & $\begin{array}{c}\text { tabulated } \\
\text { misorientation } \\
\text { [UTVW] }\end{array}$ & $\begin{array}{l}\text { deviation } \\
\text { from } \\
\text { UTVW }\end{array}$ & $\begin{array}{l}\text { boundary-plane } \\
\text { indice }\end{array}$ \\
\hline $\begin{array}{l}1 \\
2 \\
3 \\
4 \\
5\end{array}$ & $\begin{array}{ll}{\left[179^{\circ} 50\right.} & {[50 \overline{5} 2]} \\
178^{\circ} 50 & {[21 \overline{3} 7]} \\
178^{\circ} & {[34 \overline{7} 1]} \\
180 & {[20 \overline{2} 5]} \\
178^{\circ} 50 & {[10 \overline{1} 0]}\end{array}$ & $\begin{array}{l}\sum 7 \\
\sum 19(a) \\
\sum 11(b) \\
\sum 11(a) \\
\sum \text { basal } \\
\text { twin }\end{array}$ & $\begin{array}{ll}180^{\circ} & {[50 \overline{5} 2]} \\
180^{\circ} & {[3 \overline{1} \overline{2} 1]} \\
180^{\circ}[10 \overline{5} 6] \\
180^{\circ}[10 \overline{1} 2\} \\
180^{\circ}[10 \overline{1} 0\}\end{array}$ & $\begin{aligned} \Delta R & =2^{\circ} \\
\Delta R & =0^{\circ} 5 \\
\Delta R & =6^{\circ} \\
\Delta R & =5^{\circ} \\
\Delta R & =5^{\circ}\end{aligned}$ & $\begin{array}{l}(5 \overline{1} \overline{4} 0) \\
(10 \overline{1} 0) \\
(10 \overline{1} 2) \\
(10 \overline{1} 0)\end{array}$ \\
\hline $\begin{array}{r}6 \\
7 \\
8 \\
9 \\
10 \\
11 \\
12\end{array}$ & $\begin{array}{l}\text { Low angle grain-bo } \\
178^{\circ} \\
180^{\circ} \\
\left.\left.180^{\circ} \quad[1051] 1\right] 1\right] \\
176^{\circ} \\
179^{\circ} \\
\text { Low angle grain bo }\end{array}$ & $\begin{array}{l}\text { adary } \\
\sum 11(a) \\
\Sigma 19(a)\end{array}$ & $\begin{array}{ll}180^{\circ} & {[50 \overline{5} 1]} \\
180^{\circ} & {[52 \overline{3} 0]} \\
180^{\circ} & {[10 \overline{1} 1]}\end{array}$ & $\begin{array}{l}\Delta R=1^{\circ} \\
\Delta R=4^{\circ}\end{array}$ & $\begin{array}{l}(10 \overline{1} 2) \\
(112 \overline{3})\end{array}$ \\
\hline
\end{tabular}

Table 1 : Crystallographic description of grain boundaries which contain one or more dislocation networks.

We must emphaize that most bounciaries are special. Only boundaries 9 and 10 seem "general", but we may notice the possibility to describe these bounciaries with a rotation axis normal to rhombohedral planes $(10 \overline{1} 2)$; it may be equivalent to the C.A.D. mociel well established in the cubic system. This hypothesis is suported by the visualisation of a pseudo-periodic network of extrinsic aislocations, never observeci in a "general bounaary" (cf. Fig. 1) /7, 10\%.

In the boundary no 2, two dislocations networks are observed : a coarse network of extrinsic dislocations and a fine strictly periocic one of intrinsic secondary dislocations, the spacing of which is consistent with the deviation $\Delta \theta=0^{\circ} 5$ from the C.S.L $(\Sigma=19)$ experimentally obtained (fig. 2).

iii) A great number of faceted grain boundaries has been observed (fig.3). This phenomena is well known in alumina but only few structural studies at the present time exist $15-11 \%$. A crystallographic analysis of faceted grain boundaries in alumina $A$ and $B$ is detailed respectiveiy in Tables II and III. 


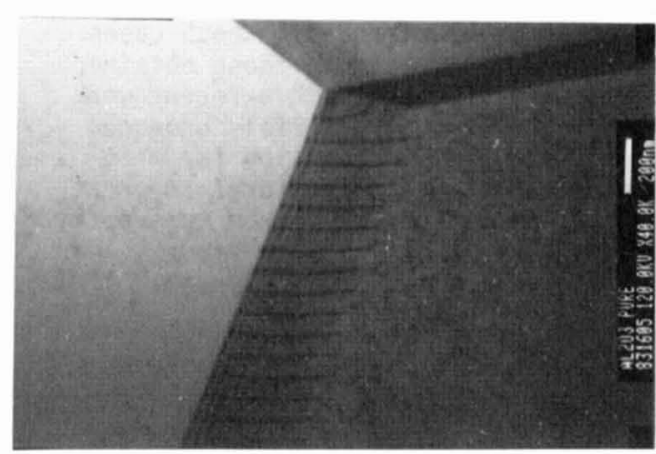

Fig. 1 : Extrinsic dislocations network observed in the $n^{\circ} 9$ boundary (cf. Table I).

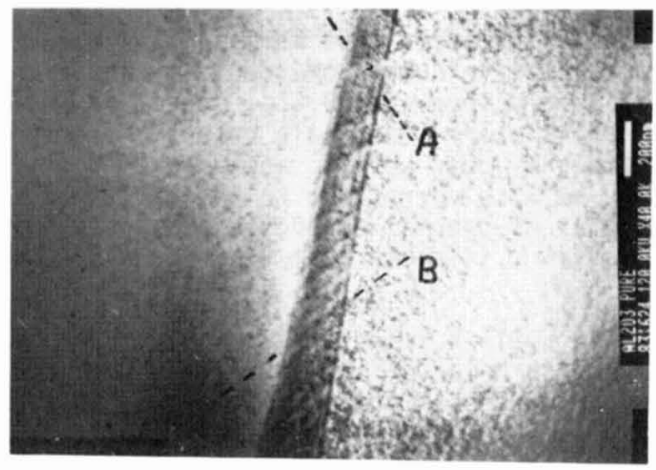

Fig.2 : Fine network of secondary intrinsic dislocations $(A)$ and coarser network of extrinsic dislocations (B) in a special $\Sigma=19(\mathrm{a})$ boundary $\left(\mathrm{n}^{\circ} 2\right.$ in table I).

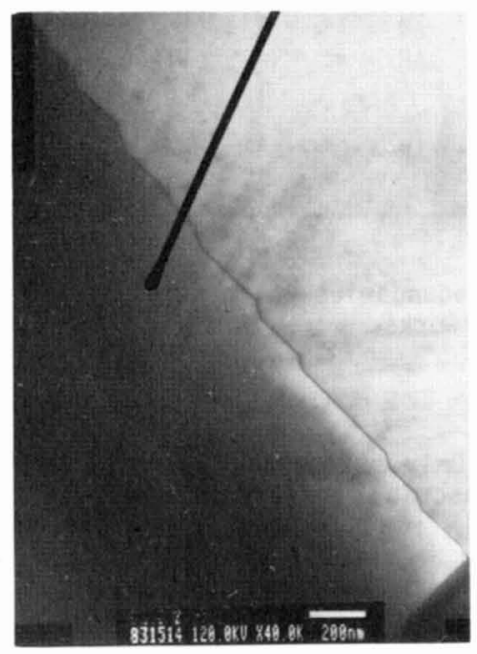

Fig.3 : Facets in the $A$ boundary (Table II) large facets are parallel to basal plane $(0001)$.
Fig.4 : a) schematic position of ions $\mathrm{O}^{--}$and $A]^{3+}$ in a symmetric tilt boundary $\Sigma=11(\mathrm{a}), \theta=$ $35^{\circ} 10[1210]$. Symmetry plane is (1011).

b) position of ions $0^{-}$and $A 7 \dot{3}+$ in the same asymmetric boundary. Boundary plane is parallel to $(10 \overline{10})$ in one grain and to (1012) in the other grain. 


\begin{tabular}{|c|c|c|c|c|c|c|}
\hline$n^{\circ}$ & $\begin{array}{r}\text { exper } \\
\text { mi sorie } \\
\theta \text { [uv }\end{array}$ & $\begin{array}{l}\text { imental } \\
\text { ntation } \\
\text { Tw? }\end{array}$ & $\underset{\Sigma}{\text { nearest }}$ & $\begin{array}{c}\text { tabulatea } \\
\text { misorientation } \\
\text { [UTVW] }\end{array}$ & $\begin{array}{l}\text { deviation } \\
\text { from } \\
\text { UTVW }\end{array}$ & $\begin{array}{c}\text { boundary-plane } \\
\text { indices }\end{array}$ \\
\hline A & $179^{\circ}$ & {$[3140]$} & $\Sigma 12 \mathrm{ex}$. & $180^{\circ} \quad[4 \overline{3} \overline{1} 0]$ & $\Delta R=5^{\circ}$ & $\begin{array}{lll}(0001) & \& & (0001) \\
(11 \overline{2} 6) & \& & (1128)\end{array}$ \\
\hline B & $177^{\circ} 50$ & {$[2 \overline{8} 61]$} & E.l2ex. & $/ 1$ & $\Delta R=5^{\circ}$ & $\begin{array}{l}(0001) \\
(1 \overline{2} 8) \& \quad(10 \overline{1} 2)\end{array}$ \\
\hline C & $179^{\circ}$ & {$[3 \overline{2} \overline{1} 0]$} & $\Sigma 7 \mathrm{ex}$. & $180^{\circ}[3 \overline{2} \overline{1} 0]$ & $\Delta R=4^{\circ}$ & \\
\hline D & $179^{\circ} 50$ & {$[37 \overline{4} 0]$} & $\Sigma 13 \mathrm{ex}$. & $180^{\circ} \quad[4 \overline{3} \overline{7} 0]$ & $\Delta R=1.5$ & $\begin{array}{l}(0001) \&(0001) \\
(11 \overline{29}) \& \&(1015)\end{array}$ \\
\hline E & $178^{\circ}$ & 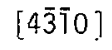 & $\sum 13 \mathrm{ex}$. & $1 /$ & $\Delta 5=6^{\circ}$ & \\
\hline $\mathrm{F}$ & $179^{\circ} 50$ & {$[10 \overline{1} 2]$} & $\Sigma 11(a)$ & $180^{\circ} \quad[10 \overline{2}]$ & $\Delta R=1^{\circ} 5$ & $(10 \overline{0} 0) \&(10 \overline{2})$ \\
\hline
\end{tabular}

Table 2

Crystallographic description of grain boundaries in alumina A which exhibit facets. (In the last column, for each boundary, the first line gives the indices of the coarsest facet in one and in the other grain; the second line concerns the small facet).

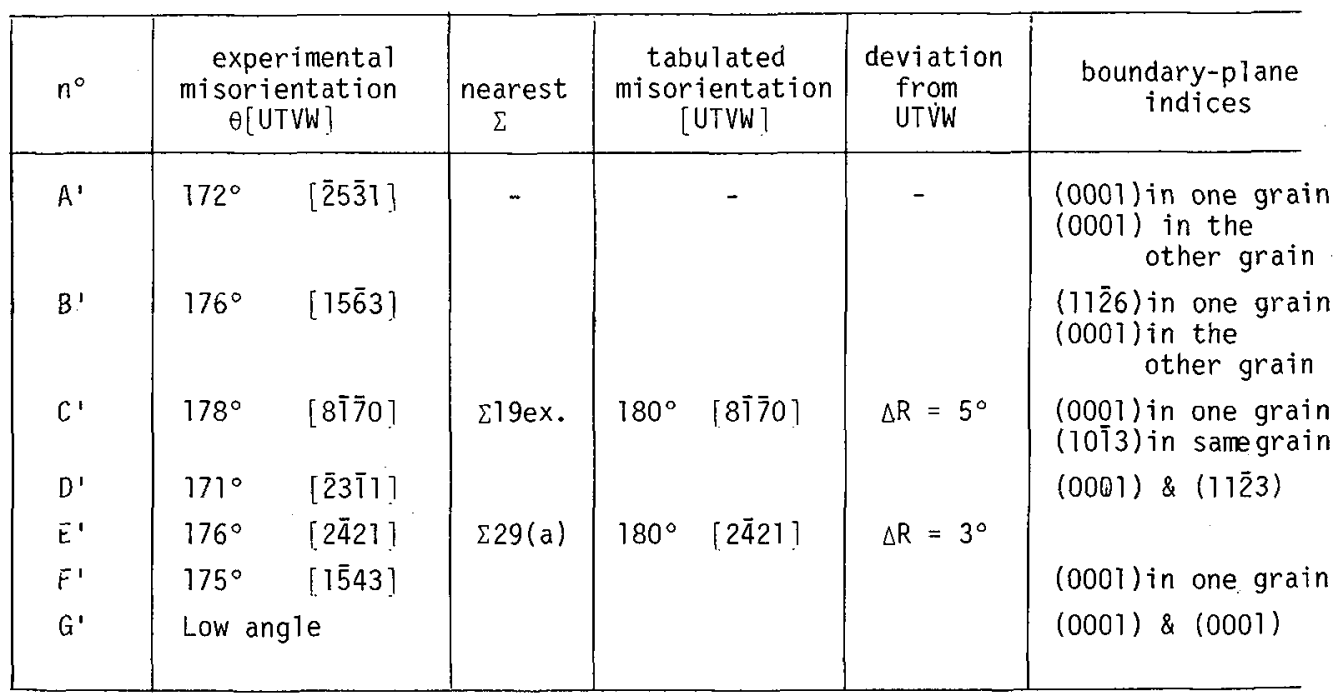

Table 3

Crystallographic description of grain boundaries in alumina $B$ which exhibit facets 
In Alumina $A$, it is worth noting that among the 65 boundaries studied, only 7 boundaries are close to an exact C.SL. orientation and 5 of them are faceted. In alumina $B$, only the boundary $C^{\prime}$ has a description near $\Sigma$ Nex. For both samples, the coarsest facets are most eften parallel to basal plane, which is the densest plane, and, in the case of $\Sigma$ Nex., the plane of highest density of coincident sites. The case of $F$ boundary is especially interesting. This special boundary $\Sigma=11(a)$ can be described by a $35^{\circ}, 10$ rotation angle around $[1120]$. An attempt is made to get a detailed analys is of the crystallography of the largest facets, the figure $4(\mathrm{a})$ is a schematic description of a $35^{\circ} \mathrm{T}$ [1120] tilt boundary with a symmetric highly coincident plane. By moving some ions from one grain to the other, a facet (10i2) in one grain will lie parallel to a facet (10ī0) in the other grain (fig. 4b), this is the experimental configuration observed for the largest facets.

In Alumina $B$, a high proportion of boundaries making a $90^{\circ}$ dihedral angle exists. of these, several are general but we must point out that in one grain, at least, their. plane is a basal one.

\section{III. - CONCLUSIONS}

The first results in this study emphasize the occurrence of numerous special boundaries in two sintered aluminas ( 99 and $99.9 \%$ purity). Some boundaries contain networks of intrinsic and extrinsic dislocations that may be explained on the basis of the near coincidence. Facets observed in some boundaries lie parallel to densely packed planes in one grain at least. Work is now carried on with alumina, doped with various solutes to analyze the influence of the valency and the size misfit.STEM microanalys is will be performed parallel to structural studies.

\section{REFERENCES}

/ I/ BOLLMANN N. "Crystals defects and crystalline interfaces", Springer Verlag, New-York, (1970).

/ 2/ WOLF D., J. de Physique, Colloque (C.6 43(1982) p. 45.

/ 3/ DELAVIGNeTte P., J. de Physique, Coll. C., 643 (1982) p.1

/ 4/ LOUDJANI M., LESAGE B., HUNTZ A.M., Proceedings of the "Journées Cêramiques 1984", Limoges. Industrie Céramique, $n^{\circ} 784$, juin 1984, p. 416.

/ 5/ HANSEN S.C., U.S. PHILIPS, Phil. Mag.A 47 (1983) 209.

/ 6/ LARTIGUE S., KHALFALLAH 0., and PRIESTER L., Rev. Phys. Appl. 17 (1982) p. 607.

/ 7/ LARTIGUE S. and PRIESTER L., Acta Met. 71, n¹1 (1983) p. 1809.

/ 8/ VINCENS J., HAGEGE S., NOUET G. and DELAVIGNETTE P., Colloque SFME, Besançon, (1981).

/ 9/ BOUCHET D., COLLIEX C., TREBBiA P., VIGNAUd, D., BEAUNIER, L., This session.

/10/ LARTIGUE S., BOUCHET D., PRIESTER L., Physical Chemistry of the Solid State : "Applications to metals and their compounds". p. 183, Ed. by P. LACOMBE, Elsevier Publishing (1984). 